\title{
Determination of Daughter Ion Formulas by Multiple Stages of Mass Spectrometry
}

\author{
Gary L. Glish, Scott A. McLuckey, and Keiji G. Asano \\ Analytical Chemistry Division, Oak Ridge National Laboratory, Oak Ridge, Tennessee, USA
}

\begin{abstract}
The ability to obtain daughter ion formulas via comparison of $\mathrm{MS}^{n}$ spectra of parent ions containing only ${ }^{12} \mathrm{C}$ with those of parent ions with one ${ }^{13} \mathrm{C}$ (from the natural ${ }^{13} \mathrm{C}$ abundance) is shown for cases in which isobaric interferences with the ${ }^{13} \mathrm{C}$-containing ion preclude the use of the conventional tandem mass spectrometric approach. This method allows the presence of isobaric daughter ions to be ascertained, and unexpected, complex dissociation pathways to be identified. A three-dimensional quadrupole ion trap is used for these experiments. Its high tandem mass spectrometry efficiency makes possible this type of experiment. ( $\mathrm{Am}$ Soc Mass Spectrom 1990, 1, 166-173).
\end{abstract}

I $t$ is well known that the naturally occurring isotopes (e.g., ${ }^{13} \mathrm{C},{ }^{37} \mathrm{Cl}$ ) provide information that is useful in the interpretation of a mass spectrum. It has been shown by several groups [1-5] that isotopic compositions of daughter ions in tandem mass spectrometric (MS/MS) spectra can be determined by selecting as the parent ion a species that contains more than one isotope of a given element. For instance, when more than one chlorine or bromine atom is in an ion, there will be several parent ions of the same elemental composition but with different masses. A particular isotopic parent ion can then be selected for MS/MS analysis, and resulting daughter ion abundance ratios can provide information on the fragmentation [2, 3]. It should be noted that the daughter ion isotopic distribution varies with the isotopic distribution of the parent ion and that it differs (in total number of peaks and/or relative intensity distribution) from that observed in the normal mass spectrum.

A more universal approach has been demonstrated by Bozorgzadeh et al. [4, 5] in which the MS/MS spectrum of a polyatomic parent ion, $\mathrm{m}^{+}$, is used in conjunction with the MS/MS spectrum of the corresponding ${ }^{13} \mathrm{C}$ - (or ${ }^{15} \mathrm{~N}$-) containing ion, $(\mathrm{m}+1)^{+}$, to determine daughter ion elemental compositions. (Similar information can be obtained from accurate mass measurements on the daughter ions [6-8].) The potential to deduce the elemental composition of an unknown daughter ion from this approach has also been shown [5]. A limitation of this method is that ions isobaric with the isotopic ion of interest can complicate or preclude accurate interpretation of the MS/MS spectrum.

This limitation can be overcome by the use of highresolution parent ion separation [9] or by the use of one or more additional stages of mass spectrometry to generate the appropriate isobar for the final stage

Address reprint requests to Gary L. Glish, Analytical Chemistry Division, Oak Ridge National Laboratory, Oak Ridge, TN 37831-6365. of MS/MS. The latter method is the topic of this report. Although conventional high-resolution mass spectrometry can provide information on isobaric fragment ions, it has been shown that ions formed in the source are not necessarily the same as ions of the same $\mathrm{m} / \mathrm{z}$ ratio formed in an MS/MS experiment [10]. Additionally, the high-resolution mass spectrum, unlike an MS/MS spectrum, provides no information about the genesis of a particular isobaric fragment ion. Multiple stages of mass spectrometry, on the other hand, can also provide information on the formation of isobaric daughter ions from different, sequential dissociation pathways.

To do such an experiment requires an instrument capable of performing at least three stages of mass spectrometry $\left(\mathrm{MS}^{3}\right)$. Additionally, the instrument must have very good MS/MS efficiency because the $(m+1)^{+}$ parent ion will be of small relative abundance when the sample from which it is derived contains only the natural isotopic abundance of ${ }^{13} \mathrm{C}$ or ${ }^{15} \mathrm{~N}$. An instrument that has these capabilities is the three-dimensional quadrupole ion trap [11]. This paper demonstrates the capability to determine daughter ion empirical formulas by multiple stages of mass spectrometry with a three-dimensional quadrupole ion trap.

\section{Experimental}

The experiments were performed with a Finnigan ion trap mass spectrometer (ITMS). The instrument was operated in the mass-selective instability mode (i.e., radio frequency (rf) only) [12] except for the parent ion isolation step. For parent ion isolation, a direct current voltage was applied to the ring electrode along with the $\mathrm{rf}$ voltage (mass-selective stability mode of operation) [13]. Following mass selection, the parent ion was kinetically excited, leading to collision-activated dissociation (CAD), by application of a supplementary rf voltage to the endcaps of the ion trap at the resonant 
frequency of the parent ion [14]. The amplitude of the supplementary $\mathrm{rf}$ voltage was typically a few hundred millivolts for the experiments reported here.

It was desirable to obtain $\mathrm{MS}^{n}$ spectra of both $\mathrm{m}^{+}$ and $(m+1)^{+}$under identical conditions so that appropriate corrections, described in Results and Discussion, could be made when there were several adjacent peaks. This also allowed the parameters for the MS/MS experiment (i.e., the supplementary rf amplitude and frequency) to remain the same, as these are somewhat dependent upon the number of ions in the ion trap [15]. To produce equal initial abundances of $\mathrm{m}^{+}$and $(\mathrm{m}+1)^{+}$for the respective experiments [where $(m+1)^{+}$represents the ion that contains one ${ }^{13} \mathrm{C}$ atom and $\mathrm{m}^{+}$represents the ion with only ${ }^{12} \mathrm{Cl}$, it was necessary to ionize for a longer time for the experiment beginning with $(\mathrm{m}+1)^{+}$than for the corresponding experiment beginning with $\mathrm{m}^{+}$. Because the samples contained only the natural abundances of the isotopes, the ionization time for the ${ }^{13} \mathrm{C}$ experiment to produce $(m+1)^{+}$was increased over that for the ${ }^{12} \mathrm{C}$ experiment to produce $\mathrm{m}^{+}$by a factor of roughly 91 (number of carbon atoms). Unfortunately, increasing the ionization time may increase the relative contribution of other reactions. The most common troublesome reaction that occurs under the experimental conditions used for this work is self-protonation to give a species isobaric with the ${ }^{13} \mathrm{C}$-containing molecular ion. The relative contribution of $(\mathrm{M}+\mathrm{H})^{+}$(from self-protonation) to the signal at the nominal $\mathrm{m} / \mathrm{z}$ value of $(M+1)^{+}$increases with ionization time. This complicates the formation of $(\mathrm{M}+1)^{+}$and $\mathrm{M}^{+}$at equal initial abundances for the respective experiments. Correct interpretation of the data is not precluded, however, provided $(\mathrm{M}+\mathrm{H})^{+}$fragments differently than $(\mathrm{M}+1)^{+}$. For the experiments discussed below, the ionization time was typically $1 \mathrm{~ms}$ for the ${ }^{12} \mathrm{C}$ experiment and $10 \mathrm{~ms}$ for the ${ }^{13} \mathrm{C}$ experiment.

All compounds used in this study were obtained from commercial vendors and were used as received. Typical (uncorrected) sample pressures were $5 \times 10^{-7}$ torr as measured by a Bayard-Alpert ionization gauge. Helium was used as a bath gas at a pressure of approximately 1 mtorr.

\section{Results and Discussion}

Three examples are given in this paper to illustrate the use of $\mathrm{MS}^{n}$ experiments to determine daughter ion formulas. In each case important information that cannot be obtained by MS/MS experiments alone is obtained by performing one or more additional stages of mass spectrometry beyond the conventional MS/MS experiment. The first example demonstrates the technique of using $\mathrm{MS}^{3}$ and $\mathrm{MS}^{4}$ on ions with dissociation pathways that lead to sets of adjacent, nonisobaric daughter ions. The second example focuses on a compound that is known to have isobaric daughter ions [8]. The third example provides a case in which both unexpected dissociation pathways and unusual ion-molecule reactions were identified by this method.

\section{2,5-Dimethylpyrrole}

The first example involves ions derived from 2,5dimethylpyrrole. A previously performed $\mathrm{MS}^{n}$ experiment (which included an ion-molecule association reaction in the sequence) showed that the protonated molecule $(m / z 96)$ undergoes a rearrangement that allows for the loss of ammonia, producing a daughter ion at $m / z 79, \mathrm{C}_{6} \mathrm{H}_{7}^{+}$[11]. In a separate $\mathrm{MS}^{n}$ experiment, it was observed that the molecular ion of 2,5dimethylpyrrole $(\mathrm{m} / \mathrm{z}$ 95) dissociates in two steps to give, as the most abundant ion in the $\mathrm{MS}^{3}$ spectrum, an ion at $m / z 78$ and an ion of low abundance at $m / z 77$ [11]:

$$
95\left(\mathrm{M}^{+\cdot}\right) \stackrel{\mathrm{MS}^{2}}{\rightarrow} 94 \stackrel{\mathrm{MS}^{3}}{\rightarrow} 78,77
$$

It is unclear from this experiment alone, however, which fragment in each of these pathways, the neutral fragment or the ion, contains the nitrogen atom. Acquiring just an MS/MS spectrum to resolve this question is precluded because the molecular ion $\left(\mathrm{M}^{+}\right)$falls at the same mass as the ${ }^{13} \mathrm{C}$-containing $(\mathrm{M}-\mathrm{H})^{+}$ion that would ordinarily serve as the parent ion.

The molecular ion $(m / z$ 95) can be induced to fragment in the ion trap with nearly $100 \%$ efficiency, and by far the most abundant daughter ion appears at $\mathrm{m} / \mathrm{z}$ 94, corresponding to $(\mathrm{M}-\mathrm{H})^{+}$. A population of ${ }^{13} \mathrm{C}$ containing $(\mathrm{M}-\mathrm{H})^{+}$ions that is not contaminated with ${ }^{12} \mathrm{C}$-only $\mathrm{M}^{+\cdot}$ can therefore be produced by isolating the ${ }^{13} \mathrm{C}$-containing molecular ion $(\mathrm{m} / \mathrm{z} 96)$ and subjecting it to CAD. The $\mathrm{m} / \mathrm{z} 95$ daughter ion produced in this manner can then be isolated and subjected to CAD. This overall process is referred to as an $\mathrm{MS}^{3}$ experiment and in this case begins with a ${ }^{13} \mathrm{C}$-containing parent ion. The final output generally displayed for an $\mathrm{MS}^{n}$ experiment, referred to as the $\mathrm{MS}^{n}$ spectrum, typically shows only the daughter ions analyzed in the last stage of mass spectrometry.

The relative signals from the $\mathrm{MS}^{3}$ spectra of the ${ }^{12} \mathrm{C}$-only and ${ }^{13} \mathrm{C}$-containing parent ions at $\mathrm{m} / \mathrm{z} 95$ and 96, respectively, are normalized to a total intensity of 100 arbitrary units and are listed in Table 1 . For the ${ }^{12} \mathrm{C}$-only parent ion, the ions at $\mathrm{m} / \mathrm{z} 78$ and 77 represent structurally distinct daughter ions (denoted $Y$ and $Z$, respectively, for this discussion and represented by cross-hatched versus solid bars, respectively, in the top of Figure 1). Considering the $m / z 77$ ion first, we find there are two possible sources, shown in eqs 2 and 3 :

$$
\begin{aligned}
& 95 \rightarrow 94 \rightarrow \mathrm{Z}(77)+\mathrm{C}+5 \mathrm{H} \\
& 95 \rightarrow 94 \rightarrow \mathrm{Z}(77)+\mathrm{N}+3 \mathrm{H}
\end{aligned}
$$


Table 1. Normalized signal intensities $($ sum $=100)$ for the region of interest in the $\mathrm{MS}^{3}$ spectra of 2,5-dimethylpyrrole

\begin{tabular}{lcc}
\hline$m / z$ & ${ }^{12} \mathrm{C}$ spectrum & ${ }^{13} \mathrm{C}$ spectrum ${ }^{\mathrm{a}}$ \\
\hline 79 & 0 & 78.4 \\
78 & 92.6 & $21.6^{\mathrm{b}}$ \\
77 & 7.4 & 0
\end{tabular}

a The amounts of ${ }^{12} \mathrm{C}$ and ${ }^{13} \mathrm{C}$ contributing to a particular mass are calculated assuming that the ratio of the two ions is the same in the ${ }^{13} \mathrm{C}$ spectrum as in the ${ }^{12} \mathrm{C}$ spectrum.

b $7.4{ }^{13} \mathrm{C}$-containing, $14.2{ }^{12} \mathrm{C}$-only.

If $\mathrm{Z}$ is formed via the reaction depicted in eq 2 , an identical ion (same $\mathrm{m} / \mathrm{z}$ ) would be observed to result from the ${ }^{13} \mathrm{C}$ parent ion losing the ${ }^{13} \mathrm{C}$ and five hydrogens. In the $\mathrm{MS}^{3}$ spectrum of $\mathrm{m} / \mathrm{z} 96$ (the ${ }^{13} \mathrm{C}-\mathrm{M}^{+\cdot}$ ) the expected contributions from $\mathrm{Z}$ at both $\mathrm{m} / \mathrm{z} 77$ (loss of ${ }^{13} \mathrm{C}$ and $5 \mathrm{H}$ ) and $m / z 78$ (loss of ${ }^{12} \mathrm{C}$ and $5 \mathrm{H}$ ) would be in the ratio of 1:5. (This is based on the statistical chance of losing ${ }^{13} \mathrm{C}$ versus that of losing ${ }^{12} \mathrm{C}$, assuming no isotope effect in fragmentation.) Assuming the total $\mathrm{Z}$
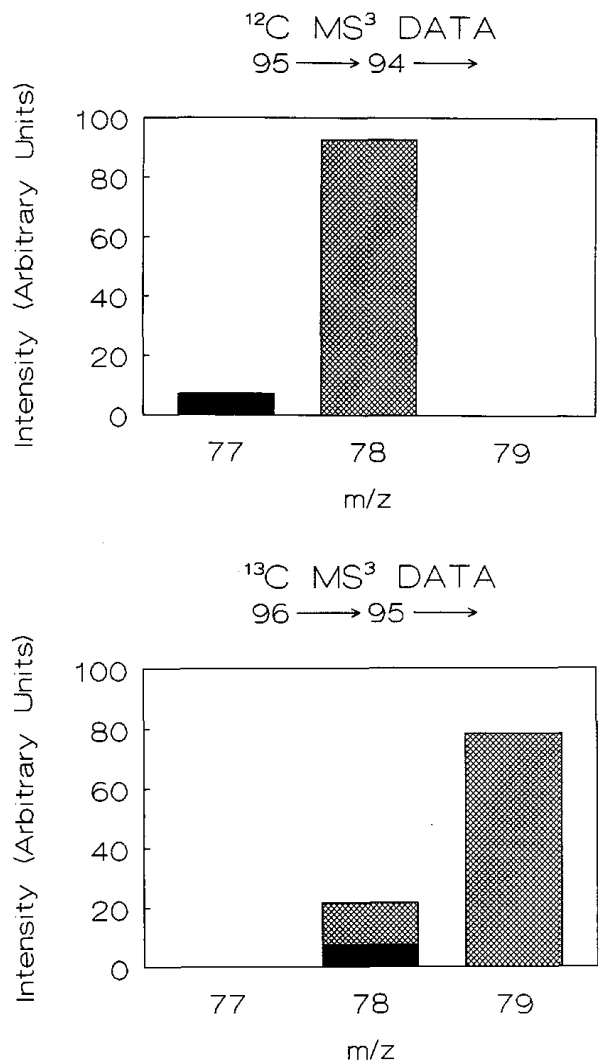

Figure 1. Plots of the $\mathrm{MS}^{3}$ data showing the contribution of the ${ }^{12} \mathrm{C}$ ionic species to the peaks in the ${ }^{13} \mathrm{C}$ spectra. The solid area represents ions of the formula of the $m / z 77$ ion (denoted $\mathrm{Z}$ in the text) in the ${ }^{12} \mathrm{C}$ spectrum, and the cross-hatched area represents ions of the formula of the $\mathrm{m} / \mathrm{z} 78$ ion (denoted $\mathrm{Y}$ in the text) in the ${ }^{12} \mathrm{C}$ spectrum of 2,5-dimethylpyrrole. intensity to be 7.4 (as in the $\mathrm{MS}^{3}$ spectrum for $\mathrm{m} / \mathrm{z}$ 95), the intensity at $m / z 77$ in the $\mathrm{MS}^{3}$ spectrum of the $\mathrm{m} / \mathrm{z}$ 96 ion should be 1.2 (1/6 of 7.4 , where $1 / 6$ is derived from the ratio of number of ${ }^{13} \mathrm{C}$ to the total number of carbons.) The data in Table 1 and the bottom of Figure 1 show that this is not observed. Because the reaction depicted in eq 3 has no carbons lost in the neutral fragment(s), $\mathrm{Z}$ in this case would be expected to move quantitatively from $\mathrm{m} / \mathrm{z} 77$ in the ${ }^{12} \mathrm{C}$ spectrum to $\mathrm{m} / \mathrm{z}$ 78 in the ${ }^{13} \mathrm{C} \mathrm{MS}^{3}$ spectrum. This is what is observed, and thus $\mathrm{Z}$ must be formed by the reaction in eq 3 and have the formula $\mathrm{C}_{6} \mathrm{H}_{5}^{+}$.

Similar logic can be applied to the two possible pathways for formation of $\mathrm{Y}$ from $\mathrm{m} / \mathrm{z}$ 95:

$$
\begin{aligned}
& 95 \rightarrow 94 \rightarrow \mathrm{Y}(78)+\mathrm{C}+4 \mathrm{H} \\
& 95 \rightarrow 94 \rightarrow \mathrm{Y}(78)+\mathrm{N}+2 \mathrm{H}
\end{aligned}
$$

For the ${ }^{13} \mathrm{C}$-containing ion, only a reaction analogous to eq 4 (i.e., eq 6) can account for the observed intensity at both $\mathrm{m} / \mathrm{z} 78$ and $\mathrm{m} / \mathrm{z} 79$ in the $\mathrm{MS}^{3}$ spectrum:

$$
96 \rightarrow 95-\left[\begin{array}{l}
Y(78)+{ }^{13} \mathrm{C}+4 \mathrm{H} \\
\mathrm{Y}(79)+{ }^{12} \mathrm{C}+4 \mathrm{H}
\end{array}\right.
$$

If it is assumed that 7.4 intensity units at $m / z 78$ in the $\mathrm{MS}^{3}$ spectrum of the ${ }^{13} \mathrm{C}$-containing parent ion are attributable to $Z$ (see below), the ratio of the peak intensities for the two $Y$ ions (78.4 at $\mathrm{m} / \mathrm{z} 79$ and $21.6-7.4=14.2$ at $\mathrm{m} / \mathrm{z} 78$ ) equals $0.18(14.2 / 78.4)$, which is quite close to the expected 1:5 ratio. The expected value follows simply from the ratio of the probability for the formation of a daughter ion with only ${ }^{12} \mathrm{C}$ to that for the formation of a daughter ion with a ${ }^{13} \mathrm{C}$ atom. For a six-carbon parent ion, this ratio is $(1 / 6) /(5 / 6)=0.20$ if the neutral fragment contains one carbon. Figure 2 is a plot of the experimental and calculated results for the two possible daughter ion formulas of $\mathrm{m} / \mathrm{z} 78$, showing the agreement between the experimental and calculated results for a daughter ion formula of $\mathrm{C}_{5} \mathrm{H}_{4} \mathrm{~N}^{+}$.

Taking the experiment one mass spectrometric stage further $\left(\mathrm{MS}^{4}\right)$, the ${ }^{12} \mathrm{C}$-only ion at $m / z 78\left(\mathrm{C}_{5} \mathrm{H}_{4} \mathrm{~N}^{+}\right)$ dissociates to ions at $m / z 51$ and $m / z 50$ :

$$
95\left(\mathrm{M}^{+\cdot}\right) \stackrel{\mathrm{MS}^{2}}{\rightarrow} 94 \stackrel{\mathrm{MS}^{3}}{\rightarrow} 78 \stackrel{\mathrm{MS}^{4}}{\rightarrow} 51,50
$$

The data for this $\mathrm{MS}^{4}$ experiment for both the ${ }^{12} \mathrm{C}$-only and ${ }^{13} \mathrm{C}$ parent ions are summarized in Table 2 and Figure 3. The ${ }^{12} \mathrm{C} /{ }^{13} \mathrm{C}$ ratio for the ions that fall at $\mathrm{m} / \mathrm{z} 52$ and $m / z 51$ in the ${ }^{13} \mathrm{C} \mathrm{MS}^{4}$ spectrum is 0.29 , whereas that for the ions at $m / z 51$ and $m / z 50$ in the ${ }^{13} \mathrm{CMS}^{4}$ spectrum is 0.23 . The expected ratio for each if the ni- 
Table 2. Normalized signal intensities (sum $=100$ ) for the region of interest in the MS ${ }^{4}$ spectra of 2,5-dimethylpyrrole

\begin{tabular}{lcc}
\hline$m / z$ & ${ }^{12} \mathrm{C}$ spectrum & ${ }^{13} \mathrm{C}$ spectrum ${ }^{\mathrm{a}}$ \\
\hline 52 & 0 & 67.6 \\
51 & 87.3 & $30.0^{\mathrm{b}}$ \\
50 & 12.7 & 2.4 \\
\hline
\end{tabular}

a The amounts of ${ }^{12} \mathrm{C}$ and ${ }^{13} \mathrm{C}$ contributing to a particular mass are calculated assuming that the ratio of the two ions is the same in the ${ }^{13} \mathrm{C}$ spectrum as in the ${ }^{12} \mathrm{C}$ spectrum.

b $10.3^{13} \mathrm{C}$-containing, $19.7^{12} \mathrm{C}$-only.

trogen is lost as part of the neutral is 0.25 ; otherwise it would be 0.67 . The $\mathrm{MS}^{4}$ spectra thus indicate that the $m / z 51$ ion in the ${ }^{12} \mathrm{C} \mathrm{MS}^{4}$ spectrum is formed by loss of $\mathrm{HCN}$ to give $\mathrm{C}_{4} \mathrm{H}_{3}^{+}$rather than by loss of $\mathrm{C}_{2} \mathrm{H}_{3}$ to give $\mathrm{C}_{3} \mathrm{HN}^{+\cdot}$ and that the $m / z 50$ ion is formed by loss of an additional hydrogen. Figures 4 and 5 are plots of the experimental results and calculated relative abundances of the possible daughter ion formulas, demonstrating again the good agreement between experimental and calculated values.

To summarize the case of 2,5-dimethylpyrrole, it is shown that the ions at $m / z 77$ and $m / z 78$ in the $\mathrm{MS}^{3}$ spectrum of the ${ }^{12} \mathrm{C}$-only molecular ion contain different numbers of carbon atoms, and the ions at $m / z 50$ and $m / z 51$ in the $\mathrm{MS}^{4}$ spectrum have the same number. This demonstrates the ability to deconvolute spectra when daughter ions arising from different reactions fall at adjacent masses and overlap in the ${ }^{13} \mathrm{C} \mathrm{MS}$ spectra (e.g., bottom part of Figure 3).

\section{3-Methyl-2-Butanone}

The second example involves ions derived from 3methyl-2-butanone. The base peak in the electron ionization (EI) mass spectrum of this compound appears at $m / z 43$ (Figure 6). High-resolution analysis of this peak has shown that it comprises the isobaric ions

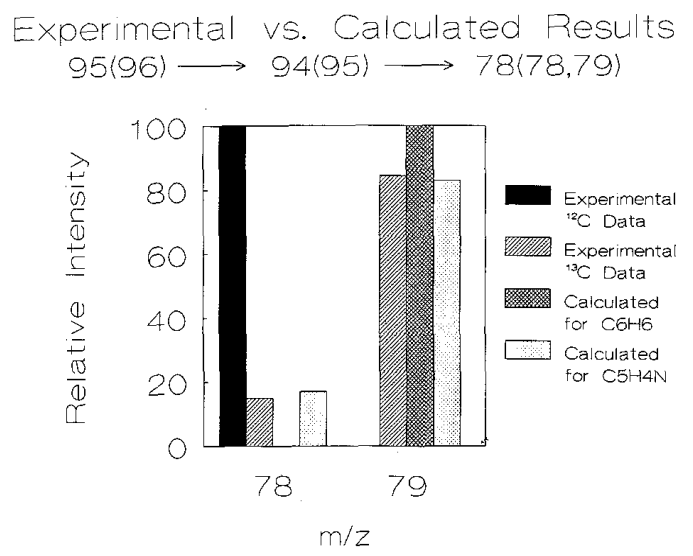

Figure 2. Plot of the experimental data $\left({ }^{12} \mathrm{C}\right.$ and $\left.{ }^{13} \mathrm{C}\right)$ and calculated values for possible formulas for the ion at $m / z 78$ in the ${ }^{12} \mathrm{C}$ $\mathrm{MS}^{3}$ spectrum of 2,5-dimethylpyrrole.
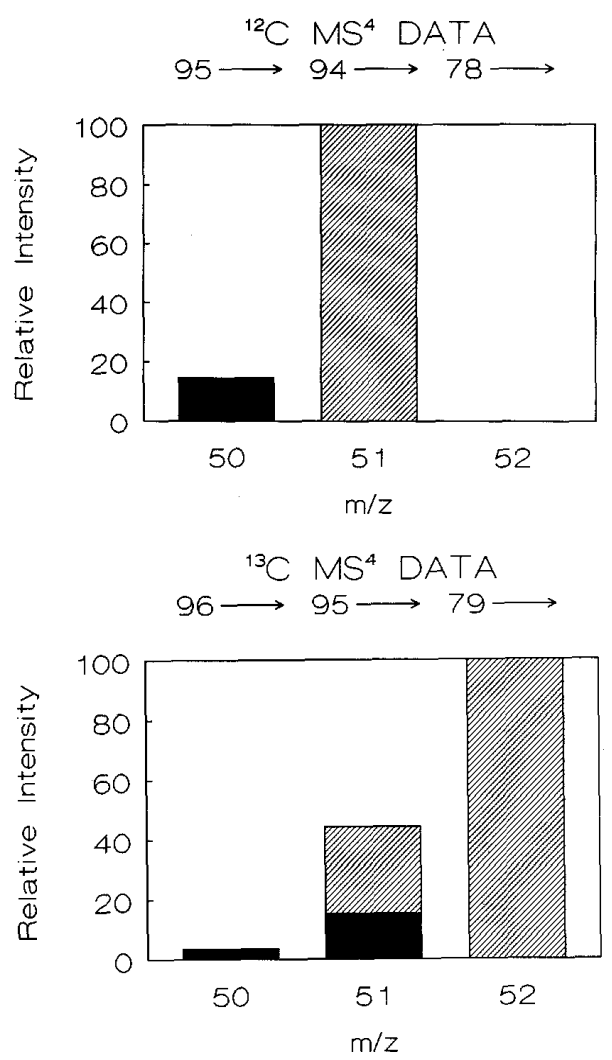

Figure 3. Plots of the $\mathrm{MS}^{4}$ data showing the contribution of the ${ }^{12} \mathrm{C}$ ionic species to the peaks in the ${ }^{13} \mathrm{C}$ spectra. The solid area represents ions of the formula of the $m / z 50$ ion in the ${ }^{12} \mathrm{C}$ spectrum, and the cross-hatched area represents ions of the formula of the $m / z 51$ ion in the ${ }^{12} \mathrm{C}$ spectrum of 2,5-dimethylpyrrole.

$\mathrm{C}_{3} \mathrm{H}_{7}^{+}$and $\mathrm{C}_{2} \mathrm{H}_{3} \mathrm{O}^{+}$. It has also been shown that these isobaric ions are in the MS/MS spectra of both the molecular ion and protonated molecule [8]. The ITMS MS/MS spectrum of the molecular ion of this compound is shown in Figure 7. The most abundant ion in

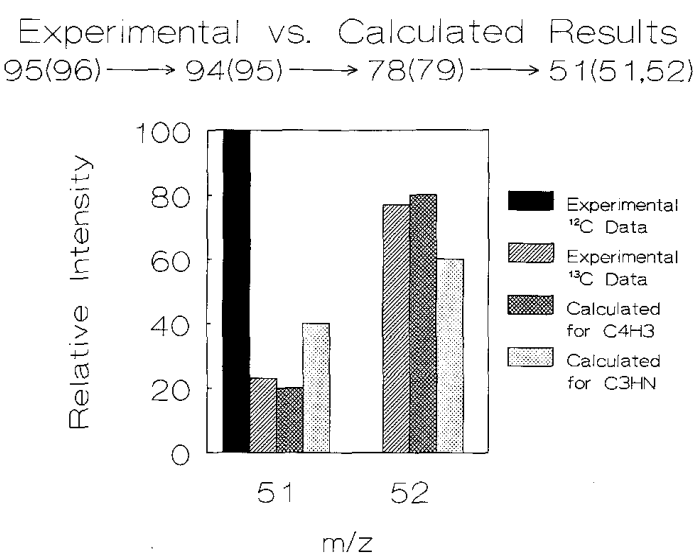

Figure 4. Plot of the experimental data $\left({ }^{12} \mathrm{C}\right.$ and $\left.{ }^{13} \mathrm{C}\right)$ and calculated values for possible formulas for the ion at $m / z 51$ in the ${ }^{12} \mathrm{C}$ $\mathrm{MS}^{4}$ spectrum of 2,5-dimethylpyrrole. 


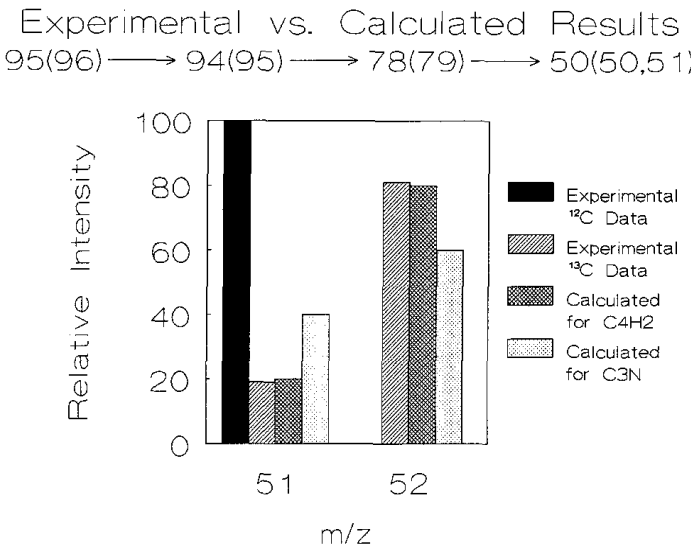

Figure 5. Plot of the experimental data $\left({ }^{12} \mathrm{C}\right.$ and $\left.{ }^{13} \mathrm{C}\right)$ and calculated values for possible formulas for the ion at $m / z 50$ in the ${ }^{12} \mathrm{C}$ $\mathrm{MS}^{4}$ spectrum of 2,5-dimethylpyrrole.

this spectrum appears at $m / z 58$, but this ion is present at less than $0.5 \%$ relative abundance in the mass spectrum. A daughter ion of almost equal abundance also appears at $m / z 71$, and a much less abundant daughter ion appears at $\mathrm{m} / \mathrm{z} 43 . \mathrm{MS}^{3}$ spectra show that the ions at both $\mathrm{m} / \mathrm{z} 71$ and $\mathrm{m} / \mathrm{z} 58$ dissociate almost exclusively to the ion of $m / z 43$.

The results from the analogous experiment for the ${ }^{13} \mathrm{C}$-containing molecular ion,

$$
86(87) \stackrel{\mathrm{MS}^{2}}{\rightarrow} 58(59) \stackrel{\mathrm{MS}^{3}}{\rightarrow} 43(43,44)
$$

show that the $m / z 58$ ion $\left(m / z 59\right.$ in the ${ }^{13} \mathrm{C}$ experiment) dissociates exclusively to $\mathrm{C}_{2} \mathrm{H}_{3} \mathrm{O}^{+}$. For the MS ${ }^{3}$ experiments,

$$
86(87) \stackrel{\mathrm{MS}^{2}}{\rightarrow} 71(72) \stackrel{\mathrm{MS}^{3}}{\rightarrow} 43(43,44)
$$

which involves the $m / z 71$ ion $\left(m / z 72\right.$ in the ${ }^{13} \mathrm{C}$ experiment), however, the ${ }^{12} \mathrm{C} /{ }^{13} \mathrm{C}$ ratio is intermediate to what would be expected if only one of the isobaric species is formed. The two-step MS/MS dissociation pathways of the molecular ion of 3-methyl-2-

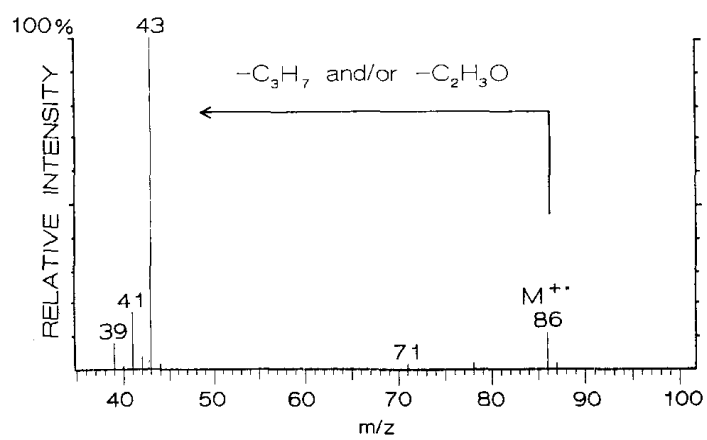

Figure 6. Quadrupole ion trap EI mass spectrum of 3-methyl-2butanone.

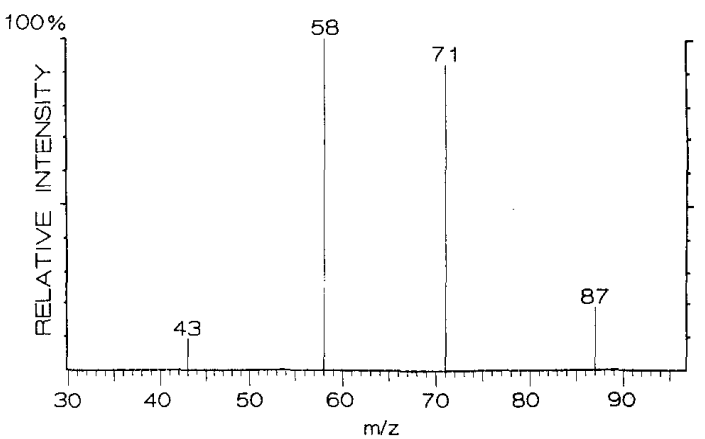

Figure 7. Tandem mass spectrometry spectrum of $\mathrm{M}^{+\cdot}(\mathrm{m} / \mathrm{z} 86)$ of 3-methyl-2-butanone. All of the parent ion was either fragmented or lost from the ion trap. (The $\mathrm{m} / z 87$ is the ${ }^{13} \mathrm{C}$ isotope peak that was not ejected from the ion trap in this experiment.)

butanone leading to an $\mathrm{m} / \mathrm{z} 43$ ion were determined from the data and are shown in bold lines in Scheme I. This scheme shows the possible dissociation pathways, the observed ${ }^{12} \mathrm{C} /{ }^{13} \mathrm{C}$ ratios (underlined at the branch points), and the calculated ${ }^{12} \mathrm{C} /{ }^{13} \mathrm{C}$ ratios for each possible dissociation path (under the possible daughter ion formulas). Figures 8 and 9 are plots of the experimental results along with the calculated values for the possible daughter ion formulas for eqs 8 and 9 , respectively. Note that because there are different intermediate ions in the $\mathrm{MS}^{3}$ sequence (i.e., $\mathrm{m} / \mathrm{z}$ 58 or 59 and $m / z 71$ or 72 , respectively), the calculated ${ }^{12} \mathrm{C} /{ }^{13} \mathrm{C}$ ratios are different even though the daughter ions are identical.

The relative contributions of the two isobars to the $\mathrm{m} / \mathrm{z} 43$ signal can be estimated from the experimental and theoretical ${ }^{12} \mathrm{C}^{13} \mathrm{C}$ ratios. The experimental result of 0.80 is equal to the sum of the weighted contribu-

$$
\begin{gathered}
\mathrm{C}_{5} \mathrm{H}_{10} \mathrm{O}^{+} \\
M W=86 \mathrm{amu}
\end{gathered}
$$

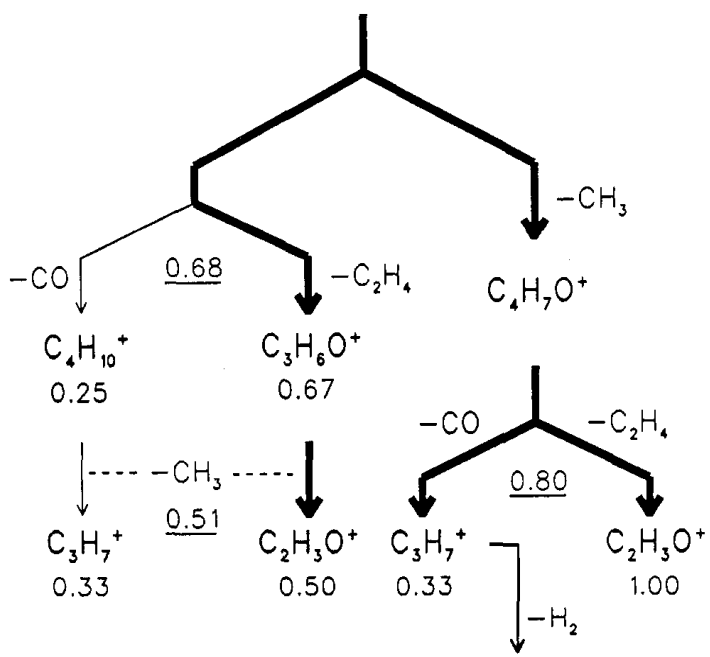

Scheme I 


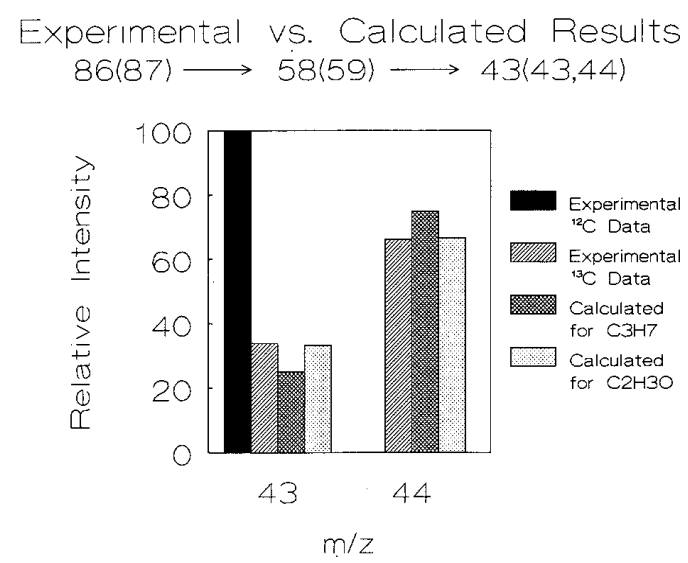

Figure 8. Plot of the experimental data $\left({ }^{12} \mathrm{C}\right.$ and $\left.{ }^{13} \mathrm{C}\right)$ and calculated values for possible formulas for the ion at $\mathrm{m} / \mathrm{z} 43$, with $\mathrm{m} / \mathrm{z} 58$ as the intermediate parent ion in the ${ }^{12} \mathrm{C} \mathrm{MS}^{3}$ spectrum of 3-methyl-2-butanone.

tions from each isobar, that is,

$$
0.80=0.33 x+1.00 y
$$

where 0.33 is the ${ }^{12} \mathrm{C}^{13} \mathrm{C}$ ratio expected if $\mathrm{m} / \mathrm{z} 43$ is composed exclusively of $\mathrm{C}_{3} \mathrm{H}_{7}^{+}, x$ is the fraction of the $\mathrm{m} / \mathrm{z} 43$ signal due to $\mathrm{C}_{3} \mathrm{H}_{7}^{+}, 1.00$ is the ${ }^{12} \mathrm{C} /{ }^{13} \mathrm{C}$ ratio expected if the $\mathrm{m} / \mathrm{z} 43$ signal is due exclusively to $\mathrm{C}_{2} \mathrm{H}_{3} \mathrm{O}^{+}$, and $y$ is the fraction of $\mathrm{m} / \mathrm{z} 43$ signal due to $\mathrm{C}_{2} \mathrm{H}_{3} \mathrm{O}^{+}$. The sum of $x$ and $y$ is 1.00 , so $x$, the fraction due to $\mathrm{C}_{3} \mathrm{H}_{7}^{+}$, is 0.3 and $y$, the fraction due to $\mathrm{C}_{2} \mathrm{H}_{3} \mathrm{O}^{+}$, is 0.7 .

Although the abundances of the ions at $m / z 71$ and $\mathrm{m} / \mathrm{z} 58$ are similar in the MS/MS spectrum of the molecular ion, the $m / z 71$ ion dissociates approximately four times as efficiently to the $\mathrm{m} / \mathrm{z} 43$ ion (based on absolute ion intensities, not shown) as the $m / z 58$ ion in the MS $^{3}$ experiments. If it is therefore assumed that $80 \%$ of the ions at $m / z 43$ in the MS/MS spectrum of the molecular

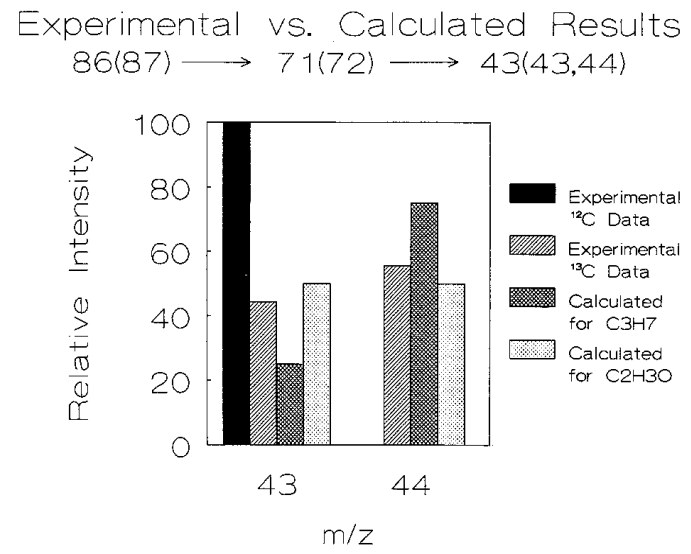

Figure 9. Plot of the experimental data $\left({ }^{12} \mathrm{C}\right.$ and $\left.{ }^{13} \mathrm{C}\right)$ and calculated values for possible formulas for the ion at $\mathrm{m} / \mathrm{z} 43$, with $\mathrm{m} / \mathrm{z} 71$ as the intermediate parent ion in the ${ }^{12} \mathrm{C} \mathrm{MS} S^{3}$ spectrum of 3-methyl-2-butanone. ion come from $\mathrm{C}_{4} \mathrm{H}_{7} \mathrm{O}^{+}$and that $20 \%$ are derived from $\mathrm{C}_{3} \mathrm{H}_{6} \mathrm{O}^{+}$, the relative contributions of the two isobars to the total signal at $m / z 43$ will be $76 \% \mathrm{C}_{2} \mathrm{H}_{3} \mathrm{O}^{+}$and $24 \% \mathrm{C}_{3} \mathrm{H}_{7}^{+}$. It is interesting to note that the MS/MS spectrum of the molecular ion of 3-methyl-2-butanone obtained using a hybrid QEB instrument [16] at a sufficient daughter ion mass resolution to resolve the isobaric $\mathrm{m} / \mathrm{z} 43$ fragments showed a relative distribution of $68 \% \mathrm{C}_{2} \mathrm{H}_{3} \mathrm{O}^{+}$and $32 \% \mathrm{C}_{3} \mathrm{H}_{7}^{+}$. The results obtained with the hybrid QEB instrument are therefore similar to the present prediction despite differences in the two instruments and rather different conditions used for $\mathrm{CAD}$.

\section{$\mathrm{N}, \mathrm{N}$-Dimethylaniline}

The last example discussed here involves ions derived from $N, N$-dimethylaniline and from trimethylphenylammonium chloride. The $\mathrm{m} / \mathrm{z} 120$ ion produced in an $\mathrm{MS}^{3}$ experiment, which began with the intact cation formed by laser desorption (LD) of trimethylphenylammonium chloride, undergoes what was thought to be unusual fragmentation (losses of 17 and $29 \mathrm{u}$ ) following collisional activation in the ITMS [17]. It was postulated that the $m / z 120$ ion should be $(\mathrm{M}-\mathrm{H})^{+}$ of $\mathrm{N}, \mathrm{N}$-dimethylaniline, so this compound was examined to confirm the LD/MS ${ }^{4}$ experiment alluded to above. The two MS/MS spectra of the $\mathrm{m} / \mathrm{z} 120$ ions derived from the two compounds are identical. The question of the composition of the unexpected daughter ions formed by losses of 17 and $29 \mathrm{u}$, respectively, remained.

The EI mass spectrum of $\mathrm{N}, \mathrm{N}$-dimethylaniline is shown in Figure 10a. As is evident in this spectrum, the normal experiment of acquiring the MS/MS spectrum of $(m+1)^{+}$was not possible because the signal at $m / z 121$ is due predominantly to the molecular ion. However, the molecular ion fragments very efficiently to $(\mathrm{M}-\mathrm{H})^{+}$as seen in the MS/MS spectrum obtained with the ITMS. This then provides for the possibility of doing an $\mathrm{MS}^{3}$ experiment (on the ${ }^{13} \mathrm{C}$-containing molecular ion at $\mathrm{m} / \mathrm{z}$ 122) to obtain the daughter ion formulas from the natural abundance of the isotopes by determining if the daughter ions contain the nitrogen atom. The spectrum in Figure $10 \mathrm{~b}$ is an $\mathrm{MS}^{3}$ spectrum obtained starting with the ${ }^{12} \mathrm{C}$-only molecular ion of $\mathrm{N}, \mathrm{N}$-dimethylaniline, and the spectrum in Figure 10c is the corresponding experiment starting with the natural ${ }^{13} \mathrm{C}$ isotope of the molecular ion.

The $m / z 120$ ion in the spectrum in Figure 10c results from a competing process in the experiment sequence (see below) and is not important in the analysis of the data to determine the composition of the daughter ions in question. Below $\mathrm{m} / \mathrm{z} 120$, the two spectra are almost identical except for the mass shifts. Table 3 lists the calculated ${ }^{12} \mathrm{C} /{ }^{13} \mathrm{C}$ ratios for the two possible isobars for each of the main daughter ions along with experimental results which, as before, have been corrected for contributions from adjacent peaks. 


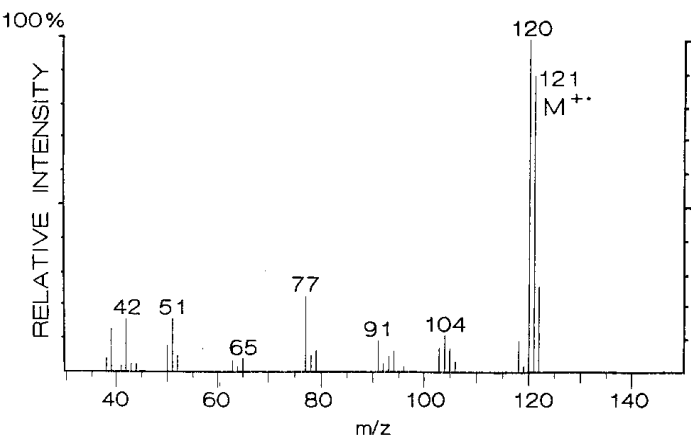

A
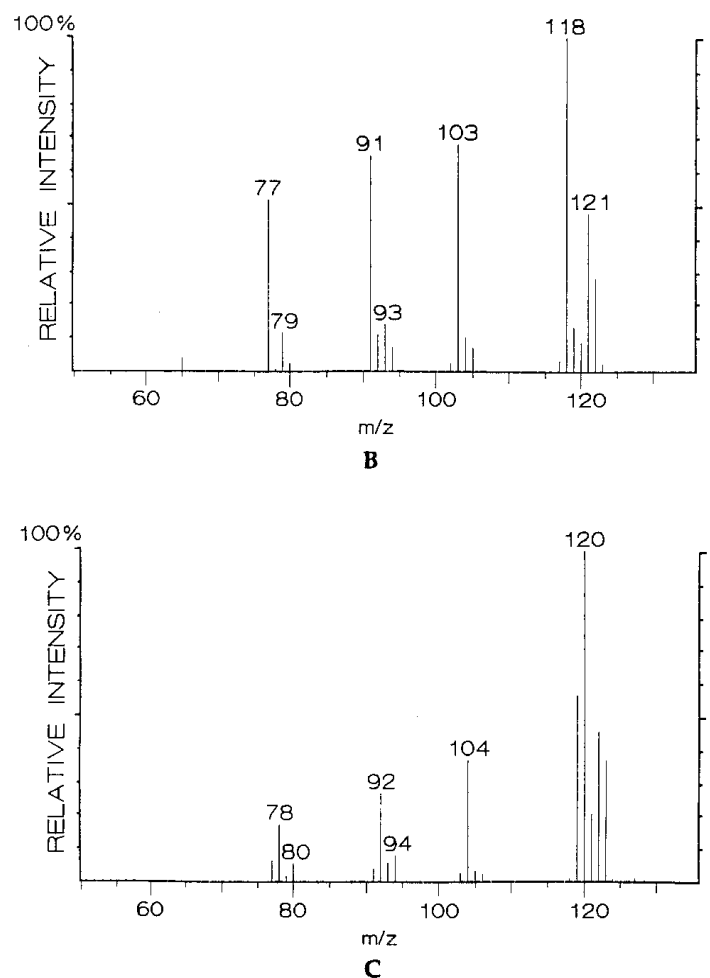

Figure 10. (a) Mass spectrum of $N, N$-dimethylaniline. (b) $\mathrm{MS}^{3}$ spectrum of $121\left({ }^{12} \mathrm{C}\right.$-only $\left.\mathrm{M}^{+}\right) \rightarrow 120 \rightarrow$ daughters. (c) $\mathrm{MS}^{3}$ spectrum of $122\left({ }^{13} \mathrm{C}\right.$-containing $\left.\mathrm{M}^{+\cdot}\right) \rightarrow 121 \rightarrow$ daughters.

These data show that the neutral fragment lost in each of these reactions contains the nitrogen. Although this is not unexpected for the $m / z 77$ daughter ion (from the ${ }^{12}$ C-only parent ion), which can be formed by a simple cleavage, a rather complex rearrangement must occur for the formation of the ions at $\mathrm{m} / \mathrm{z} 103$ (by loss of $\mathrm{NH}_{3}$ ) and $m / z 91$ (by loss of $\mathrm{CH}_{2} \mathrm{NH}$ ). [We are presently studying this system and homologues further to determine the reaction mechanism(s) and daughter ion structure(s), using the technique discussed in this paper and other $\mathrm{MS}^{n}$ experiments.]

Besides the ${ }^{12} \mathrm{C} /{ }^{13} \mathrm{C}$ ratios of the daughter ion peaks
Table 3. Calculated and experimental ${ }^{12} \mathrm{C} /{ }^{13} \mathrm{C}$ ratios for possible daughter ions from $(\mathrm{M}-\mathrm{H})^{+}$derived from $N, N$-dimethylaniline

\begin{tabular}{lccc}
\hline & & \multicolumn{2}{c}{${ }^{12} \mathrm{C} /{ }^{13} \mathrm{C}$} \\
\cline { 3 - 4 }$m / z$ & Formula & Calculated & Exptl. \\
\hline \multirow{2}{*}{103,104} & $\mathrm{C}_{7} \mathrm{H}_{5} \mathrm{~N}$ & 0.14 & 0.03 \\
& $\mathrm{C}_{8} \mathrm{H}_{7}$ & 0.00 & \\
91,92 & $\mathrm{C}_{6} \mathrm{H}_{5} \mathrm{~N}$ & 0.33 & 0.17 \\
79,80 & $\mathrm{C}_{7} \mathrm{H}_{7}$ & 0.14 & \\
& $\mathrm{C}_{5} \mathrm{H}_{5} \mathrm{~N}$ & 0.60 & 0.39 \\
77,78 & $\mathrm{C}_{6} \mathrm{H}_{7}$ & 0.33 & \\
& $\mathrm{C}_{5} \mathrm{H}_{3} \mathrm{~N}$ & 0.60 & 0.38 \\
& $\mathrm{C}_{6} \mathrm{H}_{5}$ & 0.33 & \\
\hline
\end{tabular}

of interest, there are several other features of these spectra to be noted. A notable feature of the data is the large $\mathrm{m} / \mathrm{z} 120$ peak in the ${ }^{13} \mathrm{C}$ spectrum. This peak provides evidence of another reaction taking place during the first stage of MS/MS in this experimental sequence, the charge-exchange reaction

$$
{ }^{13} \mathrm{C}-\mathrm{M}^{+\cdot}(m / z 122)+\mathrm{M} \rightarrow{ }^{13} \mathrm{C}-\mathrm{M}+\mathrm{M}^{+\cdot}(m / z 121)
$$

This is a potential problem in any trapping instrument when the neutral analyte is continuously present in the reaction region. The result here is that the $m / z 121$ ion selected for the second stage of MS/MS is a mixture of isobaric ions, the ${ }^{12} \mathrm{C}$ molecular ion along with the desired ${ }^{13} \mathrm{C}-(\mathrm{M}-\mathrm{H})^{+}$. [The charge-exchange reaction is not readily apparent in the first stage of the ${ }^{12} \mathrm{C}$ experimental sequence because it produces predominantly $(91.2 \%)$ the same ion, along with some $(8.8 \%)$ ${ }^{13} \mathrm{C}$ molecular ion.] This ${ }^{12} \mathrm{C}-\mathrm{M}^{+}$ion does not interfere with the $\mathrm{MS}^{3}$ analysis $(122 \rightarrow 121 \rightarrow$ fragments $)$ because it dissociates only to $m / z 120$ whereas the ${ }^{13} \mathrm{C}$ species dissociates to the lower mass daughter ions of interest in the experiment (i.e., ions of $m / z$ 104, 92, 78, etc.). Looking at it from a different point of view, we find that the spectrum in Figure 10c can be considered a combination of the $\mathrm{MS}^{3}$ spectrum of the ${ }^{13} \mathrm{C}$ molecular ion and the $\mathrm{MS}^{2}$ spectrum of the ${ }^{12} \mathrm{C}$ molecular ion, with the latter giving rise to just the ion at $m / z 120$.

Another, unexpected reaction can be discerned by comparing the two $\mathrm{MS}^{3}$ spectra in Figure 10. Looking only at the $\mathrm{MS}^{3}$ spectrum of the ${ }^{12} \mathrm{C}$ ion, we might deduce that the $m / z 120$ ion undergoes charge exchange and proton transfer with the neutral to give the ions at $m / z 121$ and 122, respectively. From the $\mathrm{MS}^{3}$ spectrum of the ${ }^{13} \mathrm{C}$ ion, however, it is seen that the respective ions formed are of $m / z 122$ and 123 . This suggests that the ${ }^{13} \mathrm{C}$-containing species retains the charge in the ion-molecule reaction and that one and two hydrogens are transferred to it from a neutral reactant. These results are summarized in eqs $12-15$ : 


$$
\begin{aligned}
& \left.{ }^{13} \mathrm{C}-\underset{m / z 121}{(\mathrm{M}-\mathrm{H})}\right)^{+}+\mathrm{M}+{ }^{13} \mathrm{C}-(\mathrm{M}-\mathrm{H})+\mathrm{M}^{+} \\
& { }^{13} \mathrm{C}-(\mathrm{M}-\mathrm{M}-\mathrm{H})^{+}+\mathrm{M} \rightarrow{ }^{13} \mathrm{C}-\left(\mathrm{M}^{+\cdot}\right)+(\mathrm{M}-\mathrm{H}) \\
& \left.{ }^{13} \mathrm{C}-\underset{m / z}{(\mathrm{M}-\mathrm{H} 1}-\mathrm{H}\right)^{+}+\mathrm{M}+{ }^{13} \mathrm{C}-(\mathrm{M}-2 \mathrm{M})+(\mathrm{H})+\left(\mathrm{M}+\mathrm{H}^{+}\right)
\end{aligned}
$$

$$
{ }^{13} \mathrm{C}-\underset{m / z 121}{(\mathrm{M}-\mathrm{H})^{+}}+\mathrm{M} \rightarrow \underset{m / z 123}{\stackrel{13}{ } \mathrm{C}_{-}\left(\mathrm{MH}^{+}\right)}+(\mathrm{M}-2 \mathrm{H})
$$

\section{Conclusion}

The use of multiple (i.e., more than two) stages of mass spectrometry should prove useful in cases in which isobaric (or possibly isomeric) interference precludes the use of the conventional MS/MS approach for the determination of daughter ion formulas. Such a circumstance is likely for the Finnigan ITMS (and most other MS/MS instruments), which typically affords unit mass resolution for both parent ion selection and daughter ion measurement.

The technique may be especially beneficial in studies of reaction mechanisms. It is a very simple experiment and can be done rapidly. In many cases it may be possible to perform additional stages of mass spectrometry to obtain structural information in addition to the empirical formula.

A limitation of this procedure is that it will be applicable mainly to ions that have a significant abundance in the final MS/MS spectrum or to ions whose peaks are not adjacent to those of other ions. This limitation is due to the statistical considerations associated with the fact that a limited number $\left(10^{5}-10^{6}\right)$ of ions can be stored in the ion trap. Thus small peaks in the $\mathrm{MS}^{3}$ or higher spectra will consist of a few hundred to a few thousand ions. Therefore, statistical fluctuations in the ion signal will be relatively large, making it difficult to determine accurate ${ }^{12} \mathrm{C} /{ }^{13} \mathrm{C}$ ratios.

\section{Acknowledgment}

Research was sponsored by the U.S. Department of Energy, Office of Basic Energy Sciences, under contract DE-AC05-840R21400 with Martin Marietta Energy Systems, Inc.

\section{References}

1. Bozorgzadeh, M. H.; Morgan, R. P.; Beynon, J. H. Analyst 1978, 103, 613.

2. Todd, P. J.; Barbalas, M. P.; McLafferty, F. W. Org. Mass Spectrom. 1982, 17, 79.

3. Singleton, K. E.; Cooks, R. G.; Wood, K. V. Anal. Chem. $1983,55,762$.

4. Bozorgzadeh, M. H. Rapid Commun. Mass Spectrom. 1988, 2, 61.

5. Bozorgzadeh, M. H.; Lapp, R. L.; Gross, M. L. Org. Mass Spectrom. 1988, 23, 712 .

6. Cody, R. B.; Freiser, B. S. Anal. Chem. 1982, 54, 1431.

7. Bursey, M. M.; Hass, J. R. J. Am. Chem. Soc. 1985, 107, 115.

8. Glish, G. L.; McLuckey, S. A. Anal. Chem. 1986, 58, 1887.

9. Russell, D. H.; Smith, D. H.; Warmack, R. J.; Bertram, L. K. Int. J. Mass Spectrom. Ion Phys. 1980, 35, 381.

10. Rose, M. E. Org. Mass Spectrom. 1981, 16, 323.

11. Louris, J. N.; Brodbelt-Lustig, J. S.; Cooks, R. G.; Glish, G. L.; Van Berkel, G. J.; McLuckey, S. A. Int. J. Mass Spectrom. Ion Processes, in press.

12. Stafford, G. C., Jr.; Kelley, P. E.; Syka, J. E. P.; Reynolds, W. E.; Todd, J. F. J. Int. J. Mass Spectrom. Ion Processes 1984, $60,85$.

13. Strife, R. J.; Kelley, P. E.; Weber-Grabau, M. Rapid Commun. Mass Spectrom. 1988, 2, 105.

14. Louris, J. N.; Cooks, R. G.; Syka, J. E. P.; Kelley, P. E.; Stafford, G. C., Jr.; Todd, J. F. J. Anal. Chem. 1987, 59, 1677.

15. Johnson, J. V.; Yost, R. A. Proceedings of the 36th Annual Conference on Mass Spectrometry and Allied Topics; San Francisco, CA, June 5-10, 1988, p 630.

16. Glish, G. L.; McLuckey, S. A.; Grant, B. C. to be published.

17. Glish, G. L.; Goeringer, D. E.; Asano, K. G.; McLuckey, S. A. Int. J. Mass Spectrom. Ion Processes, 1989, 94, 15. 